\title{
A socially responsible society in the era of globalization
}

\author{
Jaromír Novák $k^{1, *}$ \\ ${ }^{1}$ Palacky University Olomouc, Faculty of Physical Culture, tř́ida Míru 117, 77111 Olomouc, Czech \\ Republic
}

\begin{abstract}
Globalization is a broad-spectrum concept in its content and scope. It is not a fashionable word only. There are many causes of globalization. Human desire for cognition and transformation of living conditions can be considered as the main causes. Globalization has its economic causes; it enables higher forms of linking the material and nonmaterial values together. The influence of science and technology is also the cause of the evolution of globalization. Globalization also has communication, human and technical dimensions. Last but not least, globalization requires and enables social and ethical approaches as a decisive condition of social existence and human life. History shows that adequate attention is not paid to people. The two world wars in the last century and the wars waged in this century bear witness to that, often thanks to the so-called advanced societies. The important international organizations such as the UNO, the EU and NATO have been established to foster cooperation and peace relations between states and continents - to build a responsible global society In recent years, there has been an effort to create socially responsible companies. The whole society as for the world, continents, countries, regions, municipalities, companies and families must be socially responsible. Management belongs to human consciousness and being. Skilful management is science and art; it is a basic condition for the survival of civilization. Science and technology, and its implications, have advantages and also considerable risks. They have a share in the safety or danger of a society. Our society is increasingly determined by environmental factors such as health, air, water, soil, food, raw materials, energy and transport.
\end{abstract}

\section{Introduction}

The content and scope of the concept of globalization is extremely broad. This concept has been used for many years in many languages and many modifications according to the development of the world, according to the development of its cognition and also according to the perception of the authors of theory and those who realize the theory in practice [1]. Some creators idealize it and some creators condemn it. Some authors talk about the socalled glocalization - think globally and act locally [2-4]. According to some opinions, there

\footnotetext{
*Corresponding author : jarminov@ seznam.cz
} 
is, or will be, a departure from globalization to localization. The conditions of development can cause that globalization processes will be severely constrained for various reasons. It is difficult to predict in this era of rapid development with rapidly changing conditions [5].

With the development of a global and local society, many positive and negative things, phenomena and processes occur [6]. It seems increasingly necessary to deal with the problems of a socially responsible society. The concept of a socially responsible society is also interpreted differently. In the author's opinion, it is necessary to perceive this concept in the interest of the development of the whole world. Using the concepts of the system approach, the world can be characterized as a highly complex system with highly stochastic behaviour of its subsystems and elements. The interdependence and mutual connection can acquire critical values of behaviour and thus influence the very existence of the world [7]. The purpose of the article is to make a reference, at least in some fundamental aspects, to some problems that require cognition and solutions.

\section{Modified characteristics of globalization}

It can be stated that the concept of globalization for the purposes of this article may be based on [8]. Globalization seems to be based on the concept of globe, i.e. the roundness of the Earth. The world has become round a couple of times. For the first time, it was in the period of seafarers, especially thanks to Christopher Columbus, mariner, who discovered America and then there were other seafaring discoveries and the circumnavigation of the world. Apparently, this was the beginning of getting to know the world with the possibility of globalization. After ascertaining the possibilities and the development of seafaring, the movement of people, raw materials, food and trade exchange took place. This happened mainly for the benefit of Europe, and we have actually been coping with the consequences up to the present [9]. Further development of globalization occurred after the discovery and practical implementation of the telegraph and telephone, followed by radio communication. The development of science and technology, the emergence of cybernetics and its practical applications mean a step towards the relative shrinking of the globe [10]. The introduction of aircraft, space rockets and, unfortunately, weapon systems is a continuation of globalization. The latest major reversal of globalization is the development and implementation of advanced telecommunication technologies, which also allow an increase in the exchange of information, people, capital, transport, etc. We find ourselves in the era of cybernation with its great advantages and perhaps even greater disadvantages.

There are many reasons for globalization. It can be said that in addition to the desire to know the world and transform the conditions for a better life for mankind it is also the desire for wealth, power and domination. Economic reasons can be considered to be the main ones. Due to the possibilities of globalization, the creation of various types of values is directed to new higher levels, not always beneficial for the whole society.

Globalization also enables and requires a certain social and ethical approach as a decisive condition of social existence, human life and the preservation of the life of mankind as a whole. This creates the need and necessity for mutual cognition, understanding and, therefore, the socially responsible cooperation of all actors in the broadest sense of the word [11]. Due to science and technology, the people's interdependence is so high that its incomprehension can be destructive.

The concept of communication is modern and up-to-date. It has a number of meanings: human communication and also communication in technical terms. Both are interrelated. The technical possibilities help human communication (it is crucial) and the use of communication possibilities of technology is beneficial to man. To be noted that with the development of communication technology, a mankind is not often able to manage it. Man then becomes a part of communication technology and is a part of the "machine"; the 
misuse of communication technology also takes place. In this respect, cyberbullying, cyber espionage, cyberterrorism and other similar phenomena are increasingly occurring. For the foreseeable future, it may not be possible to prevent these harmful phenomena, but only to deal with them. In this area considerable damages and tragedies in interpersonal relations, in economic, material and financial issues, in the area of security including the military occur. The consequences may be unexpected or severely tragic.

Education and the level of education should play an important role in this area since education, inter alia, makes it possible to better distinguish between good and evil. It seems that it is exactly the opposite today. Education is rather abused. One Russian proverb says that education in the hands of a scoundrel is like a knife in the hands of a drinker.

\section{Civilization and global issues of the past with an overlap to the present}

Nowadays, man as a part of a society, is influenced by an enormous amount of information that he cannot process well enough and transform it into some individually and socially added value. This is also caused by the fact that it is not possible to reveal, which information is true or false.

Even though we are instructed about the usefulness of reflecting historical references as an experience for our existence, we do not do so to the extent necessary. Due to the effects of mass media it sometimes seems as if the existence of a society began in the twentieth century. It is a mistake. Even in the remote past, we can find many things, phenomena and processes that should and can help us understand the present.

Let's try at least a brief reminder of some past events. Using [12] let's recall the once powerful empires. It should be noted that our present perception of past processes can be deceptive. We cannot understand the then events in the then context.

The Chinese context. Once, it was the oldest advanced, dreaded and unimaginably powerful culture, nicknamed the Middle Kingdom. This giant in East Asia was based on an extremely effective form of governance (today we could say management) and on the respect it commanded. Already in the earliest times, the culture was developing in China, in which great discoveries happened centuries earlier than in the West (paper was produced hundred years before Christ, print in 868 , porcelain was produced thousand years earlier than in Europe, the invention of a compass, etc.). Despite its maturity or precisely just because of it, China, in the course of its existence (the beginning of the empire dates to about 2100 - 1600 BC) underwent a series of great reversals of the unification and division of dynasties until 1949, when the People's Republic of China and Taiwan were established. After that year, major reversals have occurred (the Cultural Revolution) and nowadays China pushes forward within the global development. There are predictions that it will be the first superpower in the world. Whether this is true and what it will bring to the world is unknown. China presents itself as a combination of socialism and capitalism.

Russia. The Russian Empire also deserves attention. It has undergone an interesting development and has shaken the world. The foundation of the city of Novgorod in the $9^{\text {th }}$ century can be considered the birth of the empire. The first Tsar was Ivan the Terrible, crowned in 1547 in Moscow. The Russian Empire underwent various reversals and violent changes. It is considered to be an empire that expanded in a staggering way; it covered one ninth of the surface of the Earth in the nineteenth century. Then, in the twentieth century, it covered one sixth of the world. Despite various losses, it survived until November 1917, when the Romanov dynasty, which had celebrated its third century in power, was overthrown in consequence of the Great October Socialist Revolution and a diverse group of fifteen republics called the Union of Soviet Socialist Republics (USSR) was formed. This large formation disintegrated as a result of revolutionary changes in the 1990s. Russia 
is no longer powerful as before. It is "tempting" by its vastness, its wealth of waters (40\% of the world's drinking water is said to be in its territory), its forests, oil, natural gas and all the elements of the Mendeleev's Periodic System. The Russian nature is also a source of strength. The Russians are said: "While the others' knees are shaking, the Russian laughs." It is difficult to anticipate what the future development of Russia will be. Despite great efforts to destroy Russia, its development is possible.

The Ottoman Empire also deserves attention. It is also remarkable for its development and, like Russia, it has affected Europe directly or indirectly. In June 1683, the Ottoman Army, made up of two hundred thousand men, encircled Vienna and put it under deadly siege. In spite of the difficult development, Vienna, and perhaps all Europe, withstood the attack. The Ottoman Empire was established in years between 1300 and 1326. It waged various wars (against Austria, Russia and the Balkans) and underwent a varied development. In 1923, the Republic of Turkey was proclaimed; thus the existence of the Ottoman Empire officially ended. In the 1950s, Turkey became a member of NATO for strategic reasons (then, it bordered on the Soviet Union). In recent years, Turkey's development has been described as undemocratic; in the Islamic world, Western civilization has lost its attractiveness. Turkey is a strong country with a large army. Its development raises fears.

The German development. Historically, Germany was a strong country with a specific mentality of the population. Nowadays, it is the strongest state in Europe, which it influences more and more. Paradoxically, it was defeated in World War II and, finally, it became the winner of the Cold War, especially after the changes in the 1990s. For centuries, Germany was fragmented and helpless, with a lack of feeling of belonging. Germany was ravaged by religious wars. Consolidation occurred gradually only after the defeat of France in 1870. In 1871, King of Prussia was proclaimed the German Emperor. Germany was developing in spite of various shocks. Germany became involved in World War I, in which it was defeated. About 20 years later, it started World War II. Currently, it is trying to be a main political authority in Europe. What its further development will be is also a global question.

The question arises to what degree the problems in these empires were of a global nature and how they affected the development of world territories in the past and to what degree they affect the present and future development of the world.

The twentieth century is considered to be a century of economic, scientific and technical development and also, first and foremost, a century of management. Unfortunately, this century was also the scene of two devastating wars that changed the world significantly. Management, science and technology were abused in these two wars, and the prospects of the world development showed themselves negatively. Humanity seems to be incorrigible.

In the second half of the twentieth century, other wars took place, partly as a result of the wars mentioned above. Let's recall the wars in Korea, Vietnam, Afghanistan, Kuwait, Yugoslavia, and the military coups in a number of countries in Africa and South America. There was also a collapse of the colonial system. And the chain of these events continues to this day.

As a result of developments in the first half of the twentieth century, some countries decided to establish international organizations. In 1945, the United Nations Organization (UNO) was established [13]. The aim and mission of the United Nations Organization is to maintain peace and security and to take effective collective measures to prevent and eliminate threats to the peace and to suppress the acts of aggression or other violations of peace; further, to achieve peace by peaceful means and in accordance with the principles of justice and international law, to regulate or resolve those international disputes or situations that could lead to a breach of the peace. 
A small reminder of history. In [14] the author writes that the best-known first peace organization in the world was the Ancient Greek Amphictyonic League established in 497 BC.

NATO was established in 1949 in response to the evolving international situation. The North Atlantic Treaty Organization gave rise to an alliance of independent states with a common interest in maintaining peace and defending their freedom through political solidarity and an adequate military force to deter and, if necessary, to avert all forms of aggression against them. NATO is a community of free states that are united by their determination to protect their security through mutual guarantees and stable relations with other states [15].

It can be stated that both major world organizations have formulated their mission and their goals in noble words. However, the reality is somewhat different. On the one hand, they manage to contribute to international cooperation and thus to the state of security and, on the other hand, they undermine this security. There are open or hidden conflicts between NATO states. There are almost hostile relations between the member states of Greece and Turkey. How does the Alliance want to deal with relations in the world when it has problems to solve relations within itself? It is no secret that the US plays a decisive role and exercises its power according to their possibilities. The role of the USA in the world is aptly described in [16]. There are more and more voices protesting against NATO and US activities not only in the world, but also within the Alliance framework.

The European Union [17] also has its mission and objectives, which are being achieved with an alternating success. This community of states has achieved and is achieving indisputable success. Unfortunately, as has been shown more and more in recent years, this organization (its members) is also in trouble for a number of reasons. The power elites of the economy and politics do not fulfil their mission for the benefit of the citizens of the European Union. People increasingly distrust the mission of the European Union and often the arrogant behaviour of their leaders and officials. However, this also applies to the behaviour of leaders in individual member states.

\section{Global and local problems of a contemporary society in the world}

War conflicts continue even at the beginning of this century. Let's recall Afghanistan, Iraq, Libya and Syria. And there are other threats.

Let's look at Europe and its development. Great Britain decided to leave the European Union after the popular vote. The question is why - what the share of the European Union is and what the share of Great Britain is. It is evident that politicians are not able to handle the so-called Brexit with an agreement. In Italy, there are problems with governments that arise with difficulties and then they break up. Migration issues have been a major problem in Europe for several years and no solution can be found. The development in Germany is not also very harmonious. It is influenced both by attitudes to migration, and by the development of the economy and also by the consequences of the reunification of Germany in the 1990s. In France there is not much harmony as well. What is the development in the former socialist countries? The conflict processes in Poland, Hungary, Slovakia, the Czech Republic, Bulgaria and Romania take place, which raises fears. So it can be summed up that the division (instead of unification) is deepening not only between the states in the European Union, i.e. between West and East or North and South, but also within the member states of the European Union. The ongoing processes are disquieting not only for Europe itself. The author is convinced that if Europe wants to survive, it must increasingly unite. Splitting Europe is harmful and indicates uncontrolled management. There is also the question of whether it is just low-quality management within Europe or a global intention 
of various structures that wish to divide Europe. The motto "Divide et impera!" (Divide and Rule!) of Roman Emperors seems to be still valid.

Social responsibility does not only apply to the companies, which, within public relations, sometimes tend to camouflage their activities, which do not benefit society or try to remedy their sins of the past. This responsibility also applies to states.

There are many factors that affect safety or danger. They are of different importance. Some of them seem to be unlikely or negligible, however, they can change and function in the complex with others. The consequences of the effects of these factors are sometimes unexpected but it is necessary to say that they are also selfishly and inexcusably expected especially in the pursuit of profit (and cost reduction). They may also apply to certain countries only.

The factors that may have a negative effect or reduce the global development potential and security include namely process management inadequate to their needs, as well as the main problem of today with a high hazard potential [18]. The author is convinced that the main risk of current and especially future development is management uncontrolled by political, financial, business and military elites.

Food security [19] is an important factor of general safety. Sufficiency of quality food is a condition of human living. Man is then a crucial element of the safety system and also the hazardousness system. The concept of food security can be perceived in two ways. In a broader sense, it can be understood as a part and a necessary condition of the existence of humanity, territories and states and thus of their security; in a narrow sense, as a safety for man.

A necessary condition of human life is to have enough food and fluids. The decisive fluid for human life is water, which is provided by nature in different composition, availability, quantity and quality. The problem of water is becoming increasingly complex and urgent.

Other conditions of the existence of a society are good health, fertile soil, availability of raw materials, types of energy, adequate transport and meeting people's needs. In these areas there are considerable problems that are difficult to be controllable and optimizable [20-22]. The author is afraid that they are not and will not be managed, and the negative consequences of this failure will endanger the very existence of humanity.

The present in the field of technical and technological development can be called cybernetization. The consequences of the cybernetics development penetrate all areas of our lives and determine them in many ways, both positively and negatively. Science is increasingly an immediate productive force; we can talk about a system, or rather systems man - science - technology - production - use. We can convince ourselves of the strengths and weaknesses of these systems and their elements constantly. There is a danger that man will become a secondary element of these technical factors.

\section{Conclusion}

The purpose of the text submitted is to recall some things, phenomena and processes, which attention should be paid to. There are many problems that require solutions. The complexity of our existence is large, and the variety of possibilities to direct things, phenomena and processes around us and within us is even larger [23]. Each of us faces the need for adequate, especially responsible, management, which is one of our most difficult tasks. The future will be dependent on how we will succeed in solving the main contradiction of the present $[24,25]$, i.e. the contradiction between the amount of information and the ability of man to transform it into production, which brings the added value in the broadest sense of the word. That is being decided today - and hopefully it is not too late since we are obviously not well prepared even for the present, not to mention the future. 


\section{References}

1. M. Vochozka, T. Kliestik, J. Kliestikova, G. Sion, Participating in a highly automated society: How artificial intelligence disrupts the job market, Economics, Management, and Financial Markets 13, 57-62 (2018)

2. A. Krizanova, L. Gajanova, M. Nadanyiova, Design of a CRM Level and Performance Measurement Model. Sustainability 10, 7, 2567 (2018)

3. E. Kicova, M. Nadanyiova, Marketing strategies in bus transport companies and its impact on increasing the competitiveness. In 15th International Scientific Conference on Globalization and its Socio-Economic Consequences (Rajecké Teplice, Slovakia, 292-296, 2015)

4. A. Krizanova, The current position and perspectives of the integrated transport systems in Slovak republic. Eksploatacja $i$ niezawodnosc - maintenance and reliability, 4, 25-27 (2008)

5. G. Brennan, How Digital Media Reshapes Political Activism: Mass Protests, Social Mobilization, and Civic Engagement, Geopolitics, History, and International Relations 10, 76-81 (2018)

6. J. Rumrill, V. Stehel, P. Durana, J. Kolencik, Does sexual objectification entail institutional power imbalances in organizations?, Contemporary Readings in Law and Social Justice 10, 100-106 (2018)

7. A.C.M. Yeo, S. Carter, and N.A. Chezulhaimee, Corporate social responsibility intervention: A catalyst to small-medium enterprise employee engagement, Psychosociological Issues in Human Resource Management 6, 38-62 (2018)

8. J. A. Jirásek, Agenda př́istích let (Praha, Professional Publishing,2006)

9. D. Matten, J. Moon, "Implicit" and "explicit" CSR: A conceptual framework for a comparative understanding of corporate social responsibility. Academy of Management review, 33, 2, 404-424 (2008)

10. W. Ali, J. G. Frynas, Z. Mahmood, Determinants of Corporate Social Responsibility (CSR) Disclosure in Developed and Developing Countries: A Literature Review, Corporate Social Responsibility and Environmental Management, 24, 4, 273-294 (2017)

11. D. Jamali, P. Lund-Thomsen, S. Jepperson, SMEs and CSR in Developing Countries. Business \& Society, 56, 1, 11-22 (2017)

12. H. Ch. Huf, Vzestup a pád mocných říši (Frýdek- Místek, Alpres, 2008)

13. Charta OSN (1945)

14. E. Beneš, Demokracie dnes a zitra (Praha, Čin, 1946)

15. Washingtonská smlouva (1949)

16. Z. Brzezinski, Volba: globální nadvláda nebo globální vedení (Praha, Mladá fronta, 2004)

17. J. Rifkin, Evropský sen (Praha, ELK, 2005)

18. J. Novák, Aktuálni problémy bezpečnosti (Žilina, Žilinská univerzita, 2011)

19. J. Novák, Potravinová bezpečnost jako subsystém obecné bezpečnosti (Brno, Univerzita obrany, 2013)

20. W. Sroka, R. Szanto, Corporate Social Responsibility and Business Ethics in Controversial Sectors: Analysis of Research Results. Journal of Entrepreneurship Management and Innovation 14, 3, 111-126 (2018) 
21. E. Stonkute, J. Vveinhardt, W. Sroka, Training the CSR Sensitive Mind-Set: The Integration of CSR into the Training of Business Administration Professionals. Sustainability 10, 3, 754 (2018)

22. A. Zygmunt, External linkages and intellectual assets as indicators of firms' innovation activities: Results from the Czech Republic and Poland, Oeconomia Copernicana 10, 291-308 (2019)

23. D. Miłek, Spatial differentiation in the social and economic development level in Poland, Equilibrium. Quarterly Journal of Economics and Economic Policy 13, 487507 (2018)

24. J. Kliestikova, CSR reporting in specific conditions of Slovak Republic. In 5th World Conference on Business, Economics and Management (BEM), Antalya, Turkey, 159167 (2017)

25. M. Nadanyiova, P. Durana, Corporate Social Responsibility as a brand valueenhancing tool. In 8th International Scientific Symposium on Economy of Eastern Croatia - Vision and Growth, Osijek, Croatia, 1225-1237 (2019) 